\title{
One-stop shopping for international medical graduates
}

Previously published at www.cmaj.ca

I nternational medical graduates will be entitled to apply for a medical licence simultaneously in all provinces under a new national electronic application process that will come into effect in 2012.

The initiative will further streamline and simplify the foreign credentialing process by building on a central electronic repository that was established a few years ago to house information from international medical graduates (IMGs) seeking to work in Canada.

In addition to all but eliminating paper-caused confusion, it will be a "onestop shop" for IMGs, says Dr. Ian Bowmer, executive director of the Medical Council of Canada. As the application will be online, "it will be more transparent and everybody will know what is required. You won't have to go to 13 different websites to find out."

The Medical Council of Canadaand the Federation of Medical Regulatory Authorities of Canada-led initiative is being undertaken with the aid of a \$2.8 million contribution from Human Resources and Skills Development Canada's Foreign Credential Recognition Program.

Currently, physicians must complete a different application for each province or territory to obtain a licence to practise within that jurisdiction. But once this national process comes into effect in late 2012, the same form will be used to apply to multiple regulatory authorities.

License applications to a province will include online access to an applicant's resumés, which will be housed in the Medical Council of Canada's Physician Credentials Repository.

An application will also include information about examinations and certifications required by a particular provincial licensing body, so IMGs can readily determine whether applications contain all the requisite components.

The new process will not replace the Medical Council of Canada evaluating exam or two-part qualifying exam needed to obtain a licentiate from the council - a prerequisite for Canadian licensure — and each province and ter-

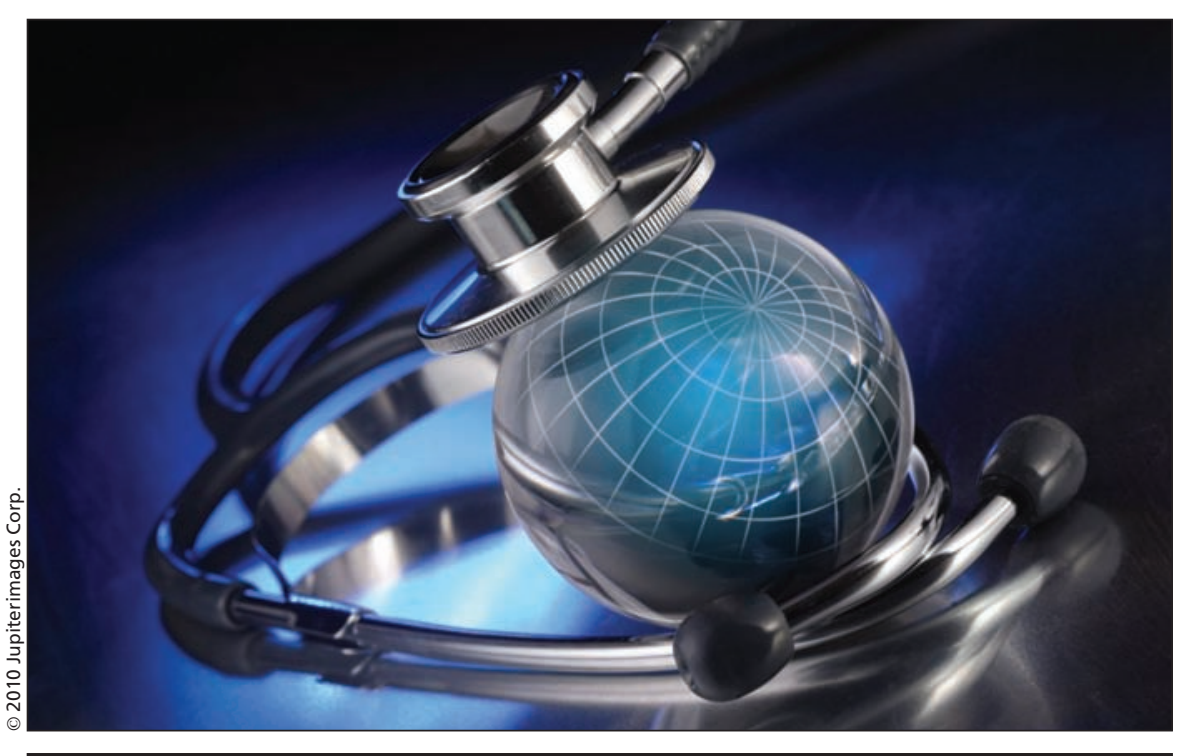

Positions are as much an obstacle as licensing procedures for international medical graduates, some physicians say.

ritory will still control its own requirements for awarding full certification.

Nor will it reduce the significant expenses that IMGs incur to become licensed. For example, taking the evaluative exam alone costs $\$ 1500$.

"The savings for IMGs coming to Canada will be through more simplicity, more understanding of the system," says Dr. Bill Lowe, president of the Federation of Medical Regulatory Authorities of Canada.

Lowe adds that it's hoped over the course of the coming two and a half years, regulatory authorities from each of the provinces and territories will be able to collaboratively produce a panCanadian application process for medical licensure which will satisfy all the licensing bodies.

But while some internationally-trained physicians say that creating a simpler application process would be "great," they suggest that the monies might be better spent on creating more positions for IMGs. An IMG has fewer opportunities to become an intern or get a job because most positions are set aside for graduates of Canadian medical schools, says Dr. Monica Herrera, president of the Association of International Medical Doctors of British Columbia.

"Right now, it doesn't matter how much you try, doesn't matter if you pass everything, you may not get it at the end," says Herrera, who was born in Chile and practised many years in Colombia before immigrating to Canada in 2003.

While the initial goal of the initiative is to simplify the application process for internationally-trained physicians, Lowe says the long-term objective is to make it easier for physicians to obtain their licences in other provinces and territories.

When the Federation of Medical Regulatory Authorities of Canada and its members became aware that some sections of a soon-to-be-finalized agreement on interprovincial trade would enable licensed physicians to relocate in other provinces or territories without further examination or assessment, they realized they needed a consensus on qualifications for pan-Canadian medical licensure, Lowe explains.

Another added benefit is that the Medical Council of Canada's credential repository will eliminate the need to repeatedly supply original documents, Lowe says, recalling the case of one doctor who had to bring in his coffee table to Nova Scotia authorities to verify his medical certificate because he'd laminated the document to its surface. - Sabrina Doyle, Ottawa, Ont.

DOI:10.1503/cmaj.109-3667 